\title{
PAZ Y EMOCIONES. HACIA UNA FENOMENOLOGÍA ERRÁTICA DEL CORAZÓN*
}

\author{
Paz e emoções. Para uma fenomenologia errática do coração \\ Peace and emotions: toward an erratic phenomenology of the heart
}

Miguel Ángel Villamil

José Miguel Cabarcas

Rubén Darío Vallejo

Wilson HERNANDO SOTO

Fray AlBeRTo RAMírEZ, O.P.

\begin{abstract}
Resumen: En la vida cotidiana, las personas suelen establecer un vínculo entre la paz y experiencias emocionales tales como la compasión con las víctimas, la venganza con los victimarios, el perdón de actos imperdonables, el terror ante la guerra, el odio entre los actores del conflicto, el reconocimiento de la culpa por actos violentos, la confianza frente a un futuro mejor, entre otras. Dicho vínculo es inadvertido o poco ponderado por las investigaciones objetivistas sobre la paz, las cuales tienden a enfatizar vínculos que consideran más válidos, como los que se refieren a las causas de los hechos violentos o a la resolución de conflictos por medio de procedimientos racionales. El presente artículo tiene un doble propósito: por un lado, sostener que las perspectivas objetivistas sobre la paz resultan insuficientes e impersonales; y, por otro lado, mostrar la paz como un ethos personal vinculado esencialmente con las experiencias emocionales.
\end{abstract}

Palabras clave: Paz, Emociones, Valoraciones, Vulnerabilidad, Dignidad.

Resumo: Na vida cotidiana, as pessoas tendem a estabelecer uma ligação entre a paz e as experiências emocionais, como a compaixão pelas vítimas, a vingança contra os perpetradores, o perdão dos atos imperdoáveis, o terror diante da guerra, o ódio entre os atores do conflito, o reconhecimento da culpa por atos violentos, a confiança num futuro melhor, entre outros. Essa ligação é despercebida ou desconsiderada pela pesquisa objetivista sobre a paz, que tende a enfatizar relacionamentos que eles consideram mais válidos, como os que se referem às causas de eventos violentos ou à resolução de conflitos por meio de procedimentos racionais. O presente artigo tem um duplo propósito: por um lado, sustentar que as perspectivas objetivistas da paz são insuficientes e impessoais; e, por outro lado, mostrar a paz como um ethos pessoal essencialmente ligado a experiências emocionais.

Palavras chave: Paz, Emoções, Avaliações, Vulnerabilidade, Dignidade.

\begin{abstract}
In everyday life, people often establish a link between peace and emotional experiences such as compassion for victims, revenge with perpetrators, forgiveness of unforgivable acts, terror before war, hatred among conflict actors, recognition of guilt for violent acts, confidence in a better future, among others. Such link is inadvertent or unweighted by objectivist investigations of peace, which tend to emphasize links that they consider more valid, such as those that refer to causes of violent acts or the resolution of conflicts through rational procedures. The present article has a dual purpose: on one hand, to maintain that the objetcivist perspectives on the peace are insufficient and impersonal; and, on the other hand, to show peace as a personal ethos essentially linked to emotional experiences.
\end{abstract}

Key Words: Peace, Emotions, Appraisal, Vulnerability, Dignity.

\section{Introducción}

La Segunda Guerra Mundial hizo de la paz un imperativo global. En consonancia con esta exigencia, las diversas naciones, de manera especial la colombiana, afrontan reto de la paz. ¿Qué es la paz? Las investigaciones objetivistas tienden a concebir la paz como un estado de cosas que puede ser explicado de manera causal, o como un estado de la mente que puede ser justificado de manera racional. De ahí que se den a la tarea de indagar relaciones entre la paz y las condiciones de estados objetivos, como las que determinan las causas de los hechos violentos, o las que determinan los procedimientos racionales que posibilitan la resolución de conflictos.

Ahora bien, en la vida cotidiana las personas suelen vincular la paz no sólo con estados objetivos, sino también con experiencias emocionales subjetivas que testimonian ethos o modos de ser particulares. Veamos algunos escenarios relacionados con el conflicto armado que ilustran el vínculo de las experiencias emocionales con el ethos de la paz: la compasión con las víctimas; la venganza con los victimarios; el perdón de actos imperdonables; el terror ante la guerra; el odio entre los actores del conflicto; el reconocimiento de la culpa por actos violentos; la memoria de las heridas que generan dolor en el alma; la tolerancia entre los adversarios; el pesimismo o el optimismo frente a nuevos proyectos

\footnotetext{
* Este artículo es resultado del proyecto de investigación "Emociones y conflictos en el cultivo de la paz. Segunda fase”, código 18015050 aprobado por la Unidad de Investigación para el Fomento y Desaarrollo de la Investigación de alto nivel de la Universidad Santo Tomás, Colombia.
} 
políticos; la confianza o la desconfianza ante los actores del conflicto; la esperanza o la desesperanza frente al porvenir; el amor que mueve a seguir luchando a pesar de los pesares. La compasión, la venganza, el perdón, el terror, el odio, la culpa, el dolor, la tolerancia, el pesimismo, el optimismo, la confianza, la esperanza, el amor, todas ellas hacen referencia a experiencias emocionales vinculadas con el ethos de la paz.

Veamos otros escenarios cotidianos distintos a los del conflicto armado. Que hagamos política sobre la paz con esquemas de violencia que tratan al otro como un enemigo antagónico y no como un adversario (Mouffe, 2002); que generemos los mayores índices de violencia en los espacios comunes de convivencia, ya sea por el ruido de los vecinos, el cuidado de las mascotas, la movilidad en el transporte público (Mockus, Murraín \& Villa, 2012); que pensemos que estamos haciendo justicia cuando nos vengamos del otro y lo ajusticiamos por propia mano (Castillejo, Rueda, Agudelo \& Quiceno, 2015); que las instituciones educativas se constituyan en campos de distintos tipos de bullying (Vega \& González, 2016); que vivamos estas experiencias advierte sobre el grado de incidencia de las experiencias emocionales en nuestras relaciones interpersonales (Villamil, 2009).

Teniendo en cuenta lo anterior, este artículo se traza un doble propósito: por un lado, sostener que las perspectivas objetivistas sobre la paz son insuficientes, pues, en su procura por la objetividad, resultan impersonales; $y$, por otro lado, plantear que la paz puede ser mostrada no sólo como la ocurrencia de un estado o modo de estar objetivo, sino también como un ethos o modo de ser personal vinculado esencialmente con las experiencias emocionales. Para el desarrollo de este propósito, llevaremos a cabo una fenomenología errática (Sáez, 2009; 2015; Villamil, 2017), la cual toma como punto de partida la siguiente pregunta: ¿Cómo acontece la paz en el mundo de la vida? La tesis que defendemos afirma que la paz es susceptible de ser investigada no sólo como un estado objetivo, sino también como el acontecer de un ethos personal que valora de manera global las experiencias emocionales y que pone en obra un saber práctico comprometido con el cuidado de la vulnerabilidad y la promoción de la dignidad de las personas. Si bien este saber práctico difiere del conocimiento objetivo que promulgan las investigaciones causales y racionales, no resulta arbitrario. Su dinamismo experiencial funge como criterio y testimonio de modos de ser concretos de paz.

Para el desarrollo de este texto, planteamos la siguiente ruta: en primer lugar, discutiremos las perspectivas que conciben la paz como un estado objetivo; en segundo lugar, a partir de una fenomenología errática del corazón, mostraremos la experiencia emocional como un dinamismo valorativo conflictivo que vincula dos potencias correlativas: la potencia problemática que afecta la vulnerabilidad de la vida personal, y la potencia resolutiva que dinamiza su dignidad; en tercer lugar, mostraremos la paz como un ethos axiológico que promueve el cultivo de un saber emocional comprometido con la vida buena de las personas.

\section{Discusión con las perspectivas objetivistas sobre la paz}

Después de la Segunda Guerra Mundial, la Organización de las Naciones Unidas (ONU) surge con el propósito de generar las condiciones de posibilidad de una paz real. Hay tres momentos fundamentales en los que la ONU exhorta a la realización de su cometido. La primera exhortación la hace en su Carta Fundacional, en donde propone como objetivo "preservar a las generaciones venideras del flagelo de la guerra que dos veces durante nuestra vida ha infligido a la Humanidad sufrimientos indecibles" (ONU, 1945). Como vemos, aquí el énfasis está puesto en el estado de cosas que genera la guerra, y la paz, entonces, es comprendida como la reconstrucción y preservación de un estado de cosas contario a ella; es decir, un estado de cosas diferente al sucedido en las dos guerras mundiales. La segunda exhortación la hace en el contexto de la fundación de la Organización de las Naciones para la Educación, la Ciencia y la Cultura (UNESCO), la cual nace con el propósito primordial de "construir la paz en la mente de los hombres mediante la educación, la cultura, las ciencias naturales y sociales y la comunicación" (ONU, 2012). Aquí el acento ya no está puesto en el hecho de la guerra, sino en el estado de la mente de los hombres y su consecuente formación. La tercera exhortación la hace en los últimos decenios bajo el lema Cultivemos la Paz. El Manifiesto 2000 plantea lo siguiente: "Reconociendo mi parte de responsabilidad ante el futuro de la humanidad, especialmente para los niños de hoy y de mañana, me comprometo en mi vida diaria, en mi familia, mi trabajo, mi comunidad, mi país y mi región a cultivar la paz" (ONU, 2000). Aquí el énfasis está puesto en la responsabilidad personal respecto al cultivo de la paz. Estas exhortaciones han promovido un horizonte investigativo sobre la paz, cuyo abordaje, a nuestro modo de ver, puede ser comprendido desde tres sendas distintas y complementarias: la investigación de los hechos, la investigación de la mente y la investigación ética de la personalidad.

En los últimos años, la Cátedra UNESCO de Filosofía para la Paz ha tomado como marco de referencia las exhortaciones de la ONU para desarrollar diversas investigaciones sobre la paz (Cortés, 2014; Martínez, 2001; 2009). Si bien es claro que estas investigaciones han sido realizadas desde diferentes perspectivas epistemológicas, consideramos que, por su aire de familia, pueden ser caracterizadas, grosso modo, como perspectivas de índole causal y racional ${ }^{1}$.

1 La agrupación en las perspectivas causal y racional permite contrastar aspectos epistemológicos clave como problemas, obje- 
La perspectiva causal ha aportado dos conceptos básicos de paz, a saber: la paz negativa y la paz positiva (Grasa, 2010). La concepción de la paz negativa surge como respuesta a las problemáticas que emergieron de las dos guerras mundiales. De ahí que defina la paz no desde sí misma, sino como un fenómeno que se caracteriza por la ausencia de guerra entre Estados nacionales. Según Rapoport, un ejemplo de definición de paz negativa es este: "Paz: tregua de guerra. Sosiego tras un litigio o desorden. Descanso tras cualquier conmoción. Quietud tras un motín o tumulto" (1999, p. 669). Vista así, la paz se logra en la medida en que se conozcan las causas de los hechos o los estados fácticos que dan lugar a la guerra y se eviten sus efectos nefastos para humanidad (ONU, 1945). Por consiguiente, el propósito principal que se traza esta perspectiva tiene un triple sentido: primero, explicar las estructuras causales de los conflictos armados entre Estados; segundo, predecir sus consecuencias; y tercero, proponer alternativas de resolución distintas a la guerra. Desde el marco investigativo trazado por teorías como la Teoría de la Diplomacia (Nicolson, 1950) y la Teoría de las Relaciones Internacionales (Norman, 1950), esta perspectiva aborda temas relacionados con el desarrollo armamentístico, el gasto militar, el comercio de armas, la seguridad nacional, el terrorismo, entre otros (Urdal, 2014). El abordaje de estos temas desde una perspectiva causal, según Grasa, toma como punto de partida "la convicción de que las causas de la guerra y las condiciones de la paz son cognoscibles, por lo que se convierten en problemas intelectuales y académicos dignos de ser estudiados y entendidos” (2010, p. 11). En este sentido, la investigación busca conocer las causas de la guerra entre Estados nacionales para evitar que sucedan, y así se consoliden las condiciones para la paz.

La concepción de la paz positiva, por su parte, critica la definición negativa de la paz como ausencia de guerra, y en su lugar aporta conceptos referentes al desarrollo humano y la violencia estructural (Galtung, 1964; 1975; 1984; 2003). Así, la paz ya no es definida en relación con los hechos o los estados fácticos que propician la guerra, sino en relación con los hechos que permiten ponderar el desarrollo humano y la violencia. Vista así, la paz expresa un proceso normativo y prescriptivo de desarrollo humano, cuyo conocimiento presta las bases para contrarrestar los distintos hechos de violencia que tengan lugar, ya sea en el interior de un Estado, o ya sea en la política externa entre Estados. De ahí que la investigación para la paz positiva se plantee como objetivo principal explicar o diagnosticar las causas de los hechos de violencia; predecir o pronosticar sus consecuencias; y establecer una tera-

tos, propósitos, metodologías, resultados y criterios de evaluación. También permite organizar las investigaciones realizadas en torno a la paz, tomando como base el logos demostrativo que caracteriza la investigación causal, y el logos argumentativo que caracteriza la investigación racional. Con este marco, pretendemos contextualizar nuestra propuesta en el panorama de discusión contemporánea planteada por autores como Martínez, Commins y París (2009), Grasa (2010), Cortés (2014), y Urdal (2014). pia o proceso normativo cuyo desarrollo posibilite un estado de paz alternativo. Para el logro de su cometido, esta perspectiva indaga, de manera cuantitativa, los indicadores económicos y políticos relacionados con las posibilidades sociales de un eventual estado de desarrollo humano (Cortés, 2014). A partir del horizonte investigativo abierto por teorías como la Teoría de Juegos (Neumann \& Morgenstern, 1944), la Teoría del Desarrollo (Rostow, 1960) y la Teoría General de Sistemas (Bertalanffy, 1976), esta perspectiva analiza temas como la renta, las capacidades, la salud, la mortalidad, la educación, entre otros. Según Galtung, "la idea es que los datos empíricos, cuidadosamente recogidos y metódicamente analizados, deben convertirse en el árbitro entre ideologías en disputa. La decisión de quién tiene más razón (...) debe tomarse a partir de la evidencia empírica existente” (1975, p. 250). En este sentido, la investigación para la paz positiva toma como base la convicción de que un eventual estado de paz se logra en la medida en que se conozcan y se pongan en práctica las condiciones causales que mejoran la condición humana, menguan la violencia en la vida social, eliminan a largo plazo la posibilidad de la guerra y aseguran la construcción de la convivencia (Grasa, 2010).

La perspectiva racional, en contraste con la perspectiva causal, ya no sitúa la paz sólo en el ámbito de los hechos -como la guerra, la violencia o el desarrollo humano- sino también en el ámbito de la mente humana. En consecuencia, ya no concibe la paz sólo como un estado fáctico, sino también como un estado de la razón. Bajo estos parámetros, la perspectiva racional aporta un concepto de paz relacionado con la mente, la cultura y la educación. Así, la investigación que tiene como objeto la educación para la paz se traza como propósito indagar, por un lado, los fundamentos teóricos de la racionalidad práctica que estructuran el ejercicio de la ciudadanía, la democracia y los Derechos Humanos Universales; y, por otro lado, indagar los criterios y procedimientos objetivos que posibilitan los diálogos, las negociaciones y los acuerdos razonables entre interlocutores que difieren en valoraciones, actitudes y comportamientos (Martínez, 2005). Desde el marco investigativo trazado por teorías como la como la Teoría de la Acción Comunicativa (Habermas, 1987), la Teoría de Conflictos (Galtung, 1984), los Estudios Culturales (Steel, 1997) y la Pedagogía Crítica (Freire, 1981), esta perspectiva desarrolla temas como la acción comunicativa, el diálogo, la argumentación crítica, el consenso, la resolución discursiva de conflictos, la educación crítica de la ciudadanía, la educación liberadora, entre otros. Bajo estos presupuestos, la perspectiva racional ya no busca explicar la paz como el resultado de relaciones causales entre hechos empíricos predecibles, sino como el resultado de las acciones justificadas bajo criterios explícitos de validez. Por consiguiente, el arbitraje objetivo ya no recaerá, en primera instancia, sobre la evidencia fáctica, sino sobre la argumentación contra-fáctica (Habermas, 1998). La perspectiva 
racional que define la paz como un estado mental parte de la convicción de que ésta se puede lograr como fruto de la formación del diálogo y el consenso entre interlocutores válidos, cuyas acciones comunicativas y políticas son susceptibles de procedimientos razonables, normativos y prescriptivos.

Si bien las perspectivas causal y racional sobre la paz difieren en sus campos de estudio, metodologías, definiciones y resultados teóricos; coinciden en un aspecto crucial: ambas consideran la paz como un estado objetivo, ya sea fáctico o mental, que puede ser anticipado a la luz de condiciones determinables según criterios impersonales. De ahí que entiendan la paz como un modo de estar, que resulta de un proceso regulativo y prescriptivo entre estados objetivos. Por ejemplo, conociendo las relaciones causales o lógicas entre un estado A y un estado B, se puede generar o anticipar un estado C. En este marco, el criterio de objetividad opera como el árbitro que permite evaluar y corregir el estado inicial en contraste con el estado final al que se aspira. En el caso de la perspectiva causal, el criterio de objetividad recae sobre las leyes causales que se derivan del estudio cuantitativo de estados fácticos como la guerra, la violencia estructural o el desarrollo humano. En el caso de la perspectiva racional, el criterio de objetividad recae sobre las reglas lógicas de los raciocinios prácticos que se derivan del estudio crítico de los estados cognitivos que justifican los diálogos y los consensos entre diversos interlocutores.

Consideramos que ambas perspectivas generan aportes significativos para el conocimiento de la paz. No obstante, en su procura de objetividad, tienden a dejar de lado una variable esencial de la paz, a saber: su arraigo personal. Esto hace que sus resultados sean impersonales y, por lo tanto, insuficientes. En primer lugar, los resultados son impersonales en la medida en que el criterio de objetividad, que funge como la instancia para evaluar los eventuales estados de paz, es ubicado en el "lugar" abstracto donde operan las leyes causales o las reglas racionales. En este "lugar", lo personal no es captado como un punto de partida apropiado para la comprensión de experiencias genuinas de la paz, sino como el caso de una regla que afirma o contradice los criterios objetivos que rigen los estados causales o racionales. Es decir, lo personal no es visto como un criterio de paz, sino como un producto regulado por los criterios objetivos de paz. El problema es que lo personal, ya sea singular o comunitario, no se muestra como un estado o un proceso entre estados; se muestra, más bien, como un modo de vida o un ethos abierto a posibilidades inéditas y creativas (Villamil, 2017, p. 23). En este sentido, las experiencias personales de paz pueden ser comprendidas no sólo como mediaciones de una regla, sino también como acontecimientos erráticos que hacen regla en su devenir (Sáez, 2015, p. 8).

En segundo lugar, los resultados de las perspectivas impersonales son insuficientes en la medida que aluden no a una paz incardinada en el mundo de la vida, sino a una paz abstracta ubicada en un "topos" normativo regulado por criterios objetivos. Nuestra tesis es que el lugar real de la paz es un ethos concreto, que compromete esencialmente las dinámicas personales e interpersonales. Por eso, consideramos que el conocimiento de la paz abstracta es necesario, ya que aporta la comprensión de condiciones causales y racionales para el desarrollo de una paz real; no obstante, es insuficiente, ya que no aborda la dinámica personal como ingrediente esencial y criterio valorativo de los ethos genuinos de la paz en el mundo de la vida. El problema es que una paz pensada como estado de cosas o de las mentes no conduce necesariamente hacia una paz vivenciada como modo de ser ético interpersonal. En consecuencia, afirmamos que la paz concreta no se muestra como un objeto de estudio distante susceptible de ser analizado desde criterios objetivos por un observador neutral desinteresado. Nuestra convicción es que la comprensión del devenir y porvenir del ethos de la paz requiere una mostración fenomenológica del dinamismo conflictivo entre seres personales posicionados y comprometidos con valoraciones éticas en el mundo de la vida: la paz más que un estado de cosas es una experiencia sui generis que testimonia un modo de ser personal. Dicha experiencia funge como el lugar de un principio encarnado: el de la personalidad con criterio (Villamil, 2017, p. 180). En concordancia con la exhortación que hace la UNESCO en el Manifiesto 2000 -la cual hace énfasis en la paz como el cultivo de la responsabilidad y el compromiso personal ante el mundo de la vida y el futuro de la humanidad- consideramos que la indagación del ethos de la paz abre un campo problemático que implica una agenda investigativa distinta a la desarrollada por la perspectiva impersonal (Martínez, Commins y París, 2009).

De ahí que resulte relevante una perspectiva que muestre la paz como un ethos comprometido con valoraciones éticas. Al respecto, consideramos que el acceso originario a este tipo de valoraciones requiere allanar una "lógica del corazón" (Scheler, 1913; 1927), pues el corazón tiene razones que la razón (causal o racional) desconoce (Pascal, 1670). Esta lógica del corazón supone tematizar una potencia fundamental del dinamismo valorativo de la paz, a saber: el aspecto emocional. Si bien las experiencias emocionales suelen ser consideradas como un ingrediente incómodo que tergiversa, confunde o estropea los estudios objetivos sobre la paz, su peso en las problemáticas y resoluciones personales es decisivo (Ferro, 2016, p. 17).

Estos asuntos nos llevan a plantear una pregunta crucial: ¿Cómo cultivar un saber emocional que promueva el ethos de la paz? Frente a este problema planteamos que el cultivo del saber emocional compromete el cultivo de la paz concreta. De ahí la urgencia de una "lógica del corazón" que comprenda la paz no sólo como un hecho social o un proceso 
cognitivo susceptible de ser explicado de manera objetiva e impersonal, sino también como el cultivo de un modo de ser personal capaz de dar respuestas inéditas y creativas a las problemáticas que emergen de los campos de juego conflictivos.

Lo anterior nos lleva a ensayar una perspectiva investigativa cualitativamente distinta, que indague por el cómo y el quién del ethos de la paz. Para ello, haremos recurso de la fenomenología errática de lo personal (Villamil, 2017). Esta fenomenología hace recurso de dos conceptos que conviene aclarar: personal y errático. Lo personal hace referencia a un ethos o modo de ser, singular o comunitario, que se caracteriza por sus valoraciones reales y posibles, y con base en ellas configura su dinamismo (Villamil, 2009). De acuerdo con Scheler, "si investigo la esencia más interior, ya sea de un individuo, de una época histórica, de una familia, un pueblo, una nación, la reconoceré y comprenderé más a fondo si he reconocido el sistema siempre articulado en algún modo de sus valoraciones fácticas y de su preferencia de valor" (1957, p. 29). Lo errático, por su parte, hace referencia a un movimiento personal errante, caracterizado por un poder autocreativo abierto a la realización de valoraciones inéditas, las cuales no están determinadas necesariamente ni por un origen ni por una meta, sino que hacen camino al andar. En concordancia con Sáez, "ser errático significa ser-en-el-tránsito. Y esta condición humana no implica su desorientación o su devenir arbitrario (...) El ser errático, por el contrario, es autocreador con criterio y normatividad" (2015, p. 18).

La fenomenología errática de lo personal nos permite mostrar lo siguiente: (1) que la paz funge como un ethos valorativo que compromete la dimensión emocional de las personas; (2) que originalmente la paz acontece no como un estado objetivo, sino como un modo de ser errático que conjuga dos potencias heterogéneas y correlativas, a saber: la vulnerabilidad céntrica y la dignidad excéntrica; (3) que la tensión dinámica y conflictiva entre estas dos potencias promueve un saber significativo, práctico, personal y errático, esto es, un ingenio emocional que emerge en el seno de la vulnerabilidad propia de un modo de ser personal, y promueve lo que ese modo de ser personal aspira llegar a ser, que es su dignidad; (4) que el cultivo del ingenio emocional errático está comprometido con la responsabilidad y la realización de proyectos de paz; (5) que la personalidad singular o comunitaria puede ser comprendida como un criterio cualitativo que permite ponderar la paz. Veamos estos asuntos de manera más detallada.

\section{La experiencia emocional como un modo de ser errático}

$\mathrm{Si}$ las experiencias emocionales constituyen una vía de acceso al ethos de la paz, entonces conviene mostrar fenomenológicamente sus aspectos esenciales. Según Sáez (2009; 2015), la experiencia humana acontece en el mundo de la vida como un juego entre dos fuerzas distintas; es decir, como un modo de ser conflictivo que pone en obra dos potencias heterogéneas, irreductibles y correlativas, a saber: la centricidad y la excentricidad. En este sentido, afirma que "Si el hombre es un ser que tiene mundo, a diferencia de una roca, es porque lo habita céntricamente, por un lado, pero también porque es capaz de situarse excéntricamente, por otro" (2009, p. 11). Tener mundo, entonces, hace referencia a una doble correlación: la que se yergue entre el mundo y las personas (correlación céntrica), y la que abre al mundo y a las personas hacia sendas erráticas de sentido y realización (correlación excéntrica).

Conbaseenestospresupuestos, yenconcordancia con la propuesta que hemos desarrollado en otro lugar (Jaramillo, Cabarcas, Villamil, Vallejo y Soto, 2018), podemos comprender las experiencias emocionales como dinamismos valorativos que ponen en juego dos potencias: la vulnerabilidad céntrica y la dignidad excéntrica. Ambos movimientos constituyen el dinamismo errático global, el cual, en el seno mismo de la experiencia emocional, correlaciona lo que se valora como importante en el mundo de la vida y el aporte de dicha experiencia para el cultivo de un proyecto personal. Es decir, ambos movimientos abren un campo de juego problemático que apela por la puesta en obra de un posicionamiento resolutivo por parte del ser personal.

La vulnerabilidad céntrica alude a la potencia que problematiza lo importante en el mundo, y así devela el carácter carencial del modo de ser personal. Las personas experimentamos problemas emocionales porque somos cuerpos vulnerables que podemos ser perjudicados, amenazados, desafiados o promovidos por potencias que no controlamos a nuestro antojo (Arnold, 1960; Camps, 2011; Lazarus, 2000; Nussbaum, 2001; Solomon, 2007). En consecuencia, los seres personales experimentamos emociones -como la ira, la vergüenza, el miedo, el amor, etc.- porque somos seres susceptibles de ser afectados por problemáticas importantes, y porque somos incapaces de controlar a nuestro antojo tales problemáticas. De ahí que la problematicidad develada por la vulnerabilidad céntrica nos mueva a valorar las situaciones como más o menos importantes a la luz de nuestras propias fragilidades.

La dignidad excéntrica, por su parte, hace referencia al potencial comprensivo y responsivo con el que ser personal se posiciona selectivamente en el curso de la situación carencial, y desde ahí busca resolver las problemáticas importantes (Waldenfels, 2006). Las personas somos dignas en la medida en que podemos poner en obra comprensiones y respuestas relativas a los problemas emocionales que nos vulneran, perjudican, amenazan, desafían o promueven. De esta manera, la dignidad excéntrica funge como la potencia resolutiva desde la cual afrontamos la potencia problemática que nos afecta 
y vulnera. Así, el modo de ser personal se autovalora como un ser dotado de un potencial dinámico y selectivo que lo capacita tanto para resolver las problemáticas que devienen en el mundo de la vida, como para forjarse una personalidad. De ahí que "la dignidad excéntrica promueva a la persona a recrear el mundo y a recrear su modo de ser, de tal forma que ambos lleguen a sintonizar con la vida buena en un mundo de la vida mejor" (Villamil, 2107, p. 61).

Para comprender mejor lo dicho, consideramos conveniente traer a colación un acontecimiento que -aunque doloroso, triste y merecedor de mucho respeto- encarna dinamismos valorativos comprometidos con la vulnerabilidad céntrica y la dignidad excéntrica de las personas. El 2 de mayo de 2002, en la población de Bojayá (Colombia), aconteció un combate entre las guerrillas denominadas Fuerzas Armadas de Colombia (FARC) y los grupos paramilitares denominados Autodefensas Unidas de Colombia (AUC). Según el Grupo de Memoria Histórica (2010, p. 35), dicho día la población se vio enlutada tras la explosión de una pipeta de gas llena de metralla que los militantes de las FARC lanzaron contra los paramilitares de las AUC, quienes se ocultaban tras el recinto de la iglesia donde se refugiaban más de 300 personas de la sociedad civil:

Hacia las once de la mañana, el tercer cilindrobomba que disparó la guerrilla rompió el techo de la iglesia, impactó contra el altar y estalló, detonando su carga de explosivos y de metralla, produciendo una gran devastación: en el suelo y hasta en los muros quedó la evidencia de los cuerpos desmembrados o totalmente deshechos, y la sangre manchó el lugar, mezclándose y perdiéndose entre los escombros. (p. 59)

Las experiencias emocionales de miedo, pánico y terror que vivieron los pobladores de Bojayá emergen de la comprensión de la situación problemática, la cual pone en evidencia la valoración del peligro que amenaza la vulnerabilidad céntrica de las personas. El testimonio del párroco Antún Ramos, quien había ayudado a refugiar a los civiles en el interior de la iglesia, explicita la comprensión de la vulnerabilidad afectada de la siguiente manera: "Rogué porque no se me fueran a acabar los feligreses. Vi gente despedazada, sin piernas ni manos... cabezas regadas, sangre, mucha sangre. Inclusive aprecié a ciudadanos corriendo mutilados” (p. 60). Las personas fueron sorprendidas por una situación problemática importante en la que la valoración de su vulnerabilidad y de su potencia vital quedaron comprometidas.

Los acontecimientos de tales experiencias problemáticas y dolorosas dinamizaron resoluciones valorativas de diversa índole. Resoluciones más o menos comprometidas con la dignidad excéntrica de las personas; acciones más o menos ingeniosas; es decir, más o menos acordes con la situación vulnerable de las víctimas:

Quienes pudieron esquivaron los escombros y los cadáveres regados por el suelo para huir aterrorizados, unos hacia las casas del barrio Bella Luz -el del extremo sur de Bellavista-, y otros hacia la parte de atrás de la cabecera, internándose en la selva en busca de la ciénaga. En la confusión muchos perdieron de vista a sus hijos, familiares o amigos, quedando presos de incertidumbre y angustia (p. 60).

También hubo otro tipo de resoluciones, como la del sacerdote Antún Ramos:

En eso sale el padre Antún, que él estaba adentro en la iglesia... sale así por todo el agua, arriesgando su vida a que le cayera una bala, y movilizando la gente a que todo el mundo nos fuéramos... en un bote rumbo para Vigía, para nosotros poder salvar la vida, porque le digo que si no hubiera sido por el padre Antún nosotros nos quedamos en Bellavista y la guerrilla acaba con todo el pueblo entero... eso ahí todo el mundo no tuvo que ver ni por sacar plata, ni por sacar lajas, ni por sacar comida, todo el mundo se fue apenas con el cuerpo, y con los brazos bogando en un bote grandísimo (p. 61).

Como vemos, las problemáticas acontecidas activan respuestas valorativas que difieren unas de otras. Éstas pueden ir desde la simple comprensión del sentido de la situación, hasta la promoción de situaciones que sean más acordes con la dignidad los seres personales vulnerados. De esta manera, las experiencias emocionales movilizan los modos de ser personales no sólo hacia la comprensión céntrica de la situación, sino también hacia la senda excéntrica de reinventar tal situación mediante respuestas más o menos inéditas y más o menos creativas. El posicionamiento de la persona ante alguna de estas sendas dependerá no sólo de la situación misma, sino también de las potencias excéntricas promovidas por el propio proyecto personal. Ahora bien, el posicionamiento frente a alguna de las sendas exploradas muestra el dinamismo responsivo del miedo como un movimiento que activa la aventura errática y exploratoria que va desde la situación en el mundo, hasta la promoción de un mundo y un modo de ser distinto. La comprensión céntrica de la situación problemática no agota el dinamismo de la experiencia del miedo. El problema importante interpela a responder, a actuar, a obrar, a transformar la situación; en suma, interpela a ingeniárselas para resolver la problemática suscitada. Así, la comprensión de la afrenta promueve la emergencia de respuestas emocionales más o menos inteligentes, más o menos creativas, más o menos acordes con los 
proyectos personales. Cualquiera sea la respuesta, la dignidad excéntrica queda comprometida con la sintonía entre la experiencia emocional y el modo de ser personal.

La experiencia del miedo relatada anteriormente, en tanto problemática y responsiva, resuena en otras experiencias emocionales, tanto propias como ajenas. Así, abre un campo valorativo que guarda sintonía con experiencias ajenas, como el odio vivenciado por algunos victimarios:

Íbamos por la mitad del río, íbamos bogando con las manos y unos pedazos de palo, y recuerdo que apenas veíamos que cruzaban las balas por encima de nosotros, y nosotros les gritábamos: iay, de por Dios! iNosotros somos civiles, tengan compasión! Y yo recuerdo que del lado de allá nos gritó uno: iQué civiles, sino paracos es que serán! iImagínese, dudando de uno en medio de toda la balacera y de todo el sufrimiento! Y ahí íbamos cuando tiraron otra pipeta, iuy, y yo no sé si cayó en la iglesia o ahí cerca, pero de allá era que salía el humo! Y ahí yo dije: iAcabaron con mi pueblo! (p. 62)

Ahora bien, la experiencia del miedo también puede resonar en otras experiencias emocionales, como la compasión vivenciada por algunas de las personas involucradas:

Entonces vinimos y le dijimos al comandante de la guerrilla: ¿Sabe qué, hermano? Tiraron una pipeta en la iglesia y mataron a un poco de gente. Dígales a sus hombres que paren el combate para sacar los heridos. Entonces él dijo: ¿Cómo así...? iNo puede ser!, y se puso a llorar... Entonces llamó y pararon esa vaina... llegó la noche y otra vez el aguacero y la tronamenta... Es como si el cielo estuviera llorando la tragedia de los atrateños, como si quisiera con las lágrimas de agua limpiar la sangre de tanto inocente que hay aquí. (p. 64)

Los anteriores ejemplos muestran diferencias cualitativas en los modos resolutivos que emergen frente a las problemáticas suscitadas por el peligro y el miedo. Estas diferencias resuenan en otro tipo de resoluciones emocionales como la venganza, la culpa o el perdón. Las víctimas de Bojayá, doce años después de la tragedia que enlutó sus vidas, expresaron públicamente lo siguiente: "Las víctimas de Bojayá quieren perdonar, pero esperan hacerlo de frente, mirando a los ojos a sus victimarios, escuchando de su voz que no volverán a ensañarse con su pueblo, que la violencia y el miedo jamás regresarán” (Hincapié, 2014). Ante esta apelación, Pastor Alape, uno de los comandantes de las Farc, expresó lo siguiente: “Tal vez es por esta razón que (los guerrilleros) ofrecieron su petición de perdón como una prueba del compromiso que tienen con la reparación de las víctimas a través del camino del diálogo, con la verdad y el reconocimiento del daño causado y como una reafirmación de su compromiso de no repetición” (Alape, 2015).

En síntesis, acontecimientos como el de Bojayá testimonian experiencias emocionales que, en tanto dinamismos valorativos que involucran la vulnerabilidad céntrica y la dignidad excéntrica, muestran la correlación de las personas con el mundo como un conflicto discordante. La tensión discordante entre la vulnerabilidad céntrica y la dignidad excéntrica promueve la emergencia de un saber valorativo que se caracteriza por ser significativo, práctico, personal y errático. Este saber es significativo en la medida en que dinamiza la comprensión de situaciones emocionales problemáticas e importantes. Es práctico en tanto dinamiza la puesta en obra de resoluciones selectivas que confrontan dichas situaciones problemáticas. Es personal en tanto expresa el modo valorativo de un ser singular implicado en el mundo. Es errático en la medida en que posiciona al modo de ser personal como un ser contingente e itinerante que si bien se encuentra arrojado a un mundo problemático vigorizado por potencias de diversa índole -como la naturaleza, la tradición, la cultura, la familia, etc.-; no obstante, está abierto a resoluciones exploratorias, inéditas y creativas. En suma, el saber emocional emerge en el seno mismo de experiencias radicales, las cuales no disponen de un origen ni de un telos definidos. Según Waldenfels, "Experiencia radical significa que no hay nada ni nadie que preceda como instancia ya acabada al acontecer de la experiencia, y que tampoco hay esencias ideales, regulaciones universales ni razones suficientes que posibiliten o funden la experiencia como acontecer de experiencia” (2006, p.136).

Las características descritas anteriormente muestran el saber emocional como un dinamismo cuyo movimiento conflictivo e integral emerge de la tensión discordante entre potencias heterogéneas. Así, el saber emocional funge como una inteligencia que dinamiza un comprender operativo abierto a nuevas y mejores conquistas personales. A este saber emocional lo podemos denominar ingenio emocional errático ${ }^{2}$. Este ingenio no hace referencia a un conocimiento impersonal y abstracto, sino a un operar inteligente encarnado en la relación de las personas con el mundo. Sáez (2009) caracteriza el ingenio de la siguiente manera:

2 Consideramos que el ingenio emocional errático difiere de la inteligencia emocional automatizada que defienden las concepciones causales, como la planteada por Goleman (1996), puesto que ésta alude a una inteligencia práctica reactiva ligada a las estructuras fisiológicas configuradas de manera pre-personal. También difiere de la inteligencia emocional mediada que defienden las concepciones racionales, como la planteada por Nussbaum (2001, 2006; 2012), puesto que ésta alude a una inteligencia significativa reflexiva que opera por medio de procesos psicológicos o lógicos. Si bien la inteligencia emocional automatizada alude a la espontaneidad, y la inteligencia emocional mediada alude a la significatividad, consideramos que ambas sesgan la inteligencia espontánea, significativa y personal que caracteriza al ingenio emocional errático. 
El ingenio es más un operar inteligente que una facultad abstracta o una competencia reglada. El ingenio, por un lado, no prospera sin la radicación operante en las cosas; es una habilidad o talento que se despierta a condición de que haya que afrontar la realidad, ya sea haciendo frente a dificultades, ya sea elevando lo que hay a la altura de su secreta riqueza. Si el mundo es siempre una realidad problemática, una red de problemas en movimiento, el ingenio es capacidad en acto para aprehenderlos (...) Al mismo tiempo, y por otro lado, se pone en obra afrontando dicha realidad problemática, mediante la creación inventiva de una trayectoria insólita, sorprendente, novedosa. Pues como actividad ligada al testigo errático, no puede dejar de responder, yendo al encuentro del problema e incidiendo en él (p. 248).

El conflicto discordante con el que tiene que habérselas el ingenio alude a "la condición paradójica de toda experiencia” (Sáez, 2009, p. 127). La experiencia emocional se muestra paradójica en tanto conjuga al unísono movimientos céntricos problemáticos y movimientos excéntricos resolutivos, los cuales están abiertos a sendas de comprensión y realización inéditas y creativas:

(Las experiencias) cursan en un proceso de encuentro, in fieri; emergen en estado naciente de la relación en su de-curso y poseen una gran diversidad de rostros, una pluralidad de formas, no susceptible de ser remitidas a una regla de fondo que las impulsase a todas o a un concepto universal que las englobase como "casos" concretos. Sólo más tarde, situados en la atalaya de un nivel de abstracción que reduce la riqueza de lo real, les damos el nombre genérico de “amor” o el de “odio” (Sáez, 2009, p. 126).

El ingenio emocional errático acontece como una organización inteligente de la experiencia emocional que sintoniza lo importante que problematiza la vulnerabilidad céntrica, con lo importante que aspira realizar la dignidad excéntrica. Así, el ingenio emocional errático dinamiza el saber práctico que promueve a las personas tanto a la comprensión de la problematicidad de lo importante en el mundo, como a su correlativa respuesta valorativa, la cual repercute no sólo en la aventura exploratoria de un mundo dado, sino también en la itinerancia y contingencia de un proyecto de vida personal inédito.

En suma, el ingenio emocional errático pone en obra un saber valorativo emergente, paradójico y desafiante, el cual posiciona al modo de ser personal en medio de un campo de juego problemático y resolutivo. Los movimientos problemáticos instan al ingenio a la escucha atenta de la situación; al testimonio de la dimensión carente y vulnerable del modo de ser personal; a la comprensión del significado valorativo de lo importante; al desciframiento de la variedad de sendas de acción abiertas por la situación inquietante. Los movimientos responsivos, por su parte, motivan el ingenio a la resolución de las situaciones inquietantes; a la conquista de la dignidad; a la praxis selectiva entre las sendas abiertas y las oportunidades; a la recreación de situaciones y mundos acordes con las expectativas de vida de las personas; al actuar disruptivo y trasgresor de hábitos y tradiciones; a la recursividad operante en el decurso y trascurso de la experiencia emocional; al ensayo de aventuras satisfactorias; a utopías inéditas y creativas; en suma, a la personalización del modo de estar personal y de su porvenir vocacional. Estos movimientos dinamizan las corazonadas que el ingenio emocional errático pone en obra en su trasegar. Ahora bien, estas corazonadas pueden ser más o menos afinadas con el ethos de la paz; más o menos saludables respecto al mundo y al modo de ser personal. De ahí que convenga, por un lado, explicitar los criterios y compromisos éticos del ingenio emocional errático; y, por otro lado, mostrar cómo operan éstos en el ethos de la paz.

\section{El ethos de la paz como criterio ético para el cultivo del ingenio emocional errático}

Un problema que se le plantea a las teorías personales sobre la emoción alude a sus criterios de validez. Ahora bien, si los criterios de nuestra propuesta contrastan con los aportados por las concepciones objetivistas e impersonales, entonces: ¿Qué significa tener criterio personal? ¿Cuáles son los criterios que permiten valorar la validez del ingenio emocional errático en tanto potencia dinamizadora del cultivo de la paz? El abordaje de estas preguntas exige confrontar dos prejuicios: el de la ilustración y el de la contra-ilustración (Sáez, 2009, p. 297). El prejuicio de la ilustración plantea que la objetividad de un saber exige el hallazgo de criterios universales fundados en un concepto de racionalidad, ya sea causal o cognitiva (Nussbaum, 2001; 2006; 2012; Prinz, 2004; 2007). En este sentido, la evaluación de la validez de una experiencia emocional en relación con el cultivo de la paz dependerá de su adecuación al criterio de racionalidad. El prejuicio de la contra-ilustración, por su parte, critica cualquier tipo de generalización y considera sólo la validez de la singularidad. De ahí que bajo este prejuicio se evalúe como irrelevante la búsqueda de criterios y reglas universales. La explicitación del criterio personal de la paz implica ubicar dicho criterio en coordenadas diferentes a las planteadas por los dos prejuicios reseñados. De acuerdo con Sáez, "el tener criterio es un fenómeno de carácter práctico que involucra todo un modo de posicionarse ante los problemas" (2009, p. 299). Si bien este modo de posicionarse envuelve variables como la genética, la evolución, la historicidad, la cultura, la reflexión, los rasgos del carácter, etc.; no obstante, estas 
variables quedan integradas y trascendidas por el ejercicio de una personalidad que encarna una potencia inédita y creativa:

El ingenio opera al afrontar problemas. En el encuentro con la realidad problemática se las ingenia para ofrecer una respuesta. Quiere ello decir que la normatividad del pensamiento reside en su ejercicio y que no opera por aplicación de criterios dados en un cielo de las ideas o en un corpus categorial de la razón, que es una virtus o potencia creativa (Sáez, 2009, p. 299).

El cultivo de un ingenio emocional errático que promocione el ethos de la paz requiere una "lógica del corazón”, la cual muestre la paz no sólo como un hecho social o un proceso cognitivo susceptible de ser explicado de manera objetiva e impersonal, sino también como la puesta en juego de una potencia capaz de dar respuestas inéditas y creativas a las problemáticas que emergen de los conflictos interpersonales. El criterio de esta "lógica del corazón”, que orienta la valoración de las experiencias genuinas de paz, puede ser comprendido como el principio genésico de la vida buena (Sáez, 2009; Villamil, 2017). Según este criterio, una experiencia de paz es aquella en la que el ingenio emocional errático sintonice con el cuidado de la vulnerabilidad y la promoción de la dignidad de los modos de ser personales en el mundo. Por consiguiente, un ethos de paz no es una vida sin conflicto, sino una vida cuyas experiencias conflictivas tienden hacia el cuidado y la promoción de la vida buena, ya sea propia o ajena, ya sea real o posible. En contraste, un ethos violento es aquel cuyas experiencias conflictivas tienden a inmovilizar, paralizar o depotenciar el dinamismo de la vida buena de las personas. Visto de esta manera, el principio genésico de la vida buena no emerge como algo estático, abstracto e impersonal, sino como un juego axiológico dinámico, encarnado y personal. El lugar y el tiempo cualitativos donde acontece este principio es el testimonio de personalidades con criterio. Es decir, es en las experiencias cuyo ingenio emocional errático testimonie el cuidado de la vulnerabilidad y la promoción de la dignidad de las personas donde encontraremos el criterio inmanente de la lógica del corazón que nos permite captar la paz.

Si bien el ingenio emocional errático no está determinado por principios causales o racionales, consideramos que su ejercicio requiere ser reconocido como la expresión de un logos cualitativo, una lógica del corazón, que hace comprensibles distintos testimonios valorativos, ya sean de paz, violencia $\mathrm{u}$ otros tipos. Este logos cualitativo no es arbitrario. Al contrario, puede expresar la dinámica valorativa no sólo de un testimonio, sino también de una sabiduría emocional de la paz. Esta sabiduría reta al ingenio a poner en juego de manera habitual experiencias que sintonicen con el criterio genésico de la vida buena, el cual difiere cualitativamente de los criterios que operan en el seno de las éticas impersonales de corte causal -como la planteada por Prinz (2004; 2007)- y de corte racional -como la planteada por Nussbaum (2001; 2006)-. En concordancia con autores como Aranguren (1994), Solomon (2007), Scheler (1913) y Zubiri (1986), comprendemos el término sabiduría no como el ejercicio de un saber formal vinculado a reglas y criterios externos al dinamismo personal, sino como un saber personal errático comprometido con el dinamismo genésico de la vida buena en un mundo mejor. En este sentido, el ingenio emocional errático requiere ser comprendido como el órgano axiológico de un ethos dinámico y encarnado, cuyas corazonadas pueden sintonizar más o menos con el criterio vital de la sabiduría emocional de la paz: cuidado de la vulnerabilidad céntrica de la vida y promoción de su dignidad excéntrica.

Por consiguiente, el principio genésico de la vida, que funge como el criterio testimonial del sabio ético, requiere ser comprendido no como algo que esté antes, después o fuera de las experiencias emocionales. Al contrario, requiere ser captado como el corazón que dinamiza dichas experiencias. La salud de este corazón, que es puesta en obra por la personalidad de un sabio ético, abre un campo testimonial que liga los movimientos céntricos y excéntricos en pro del dinamismo genésico de la vida. De esta manera, el testimonio del sabio ético abre un campo errático de ob-ligaciones, esto es, ligaciones que emergen del corazón mismo de la vida y que comprometen su modo de ser con la salud del mundo y con la salud de la vida en este mundo. Tales ob-ligaciones no aluden a mandatos externos e impersonales (Aranguren, 1994; Cortina, 2009; Zubiri, 1986). Aluden, más bien, a los compromisos valorativos originarios que ligan el posicionamiento del ingenio con la salud dinámica de la vida buena. Ahora bien, estas ob-ligaciones pueden ser promovidas por modos de ser sabios, como es el caso de personalidades que dinamizan la paz; pero también pueden ser devaluadas y depotenciadas por modos de ser necios, como es el caso de personalidades violentas. Lo relevante es que ambos casos comprometen el posicionamiento del ingenio emocional errático con la salud cordial de la vida. Ahora veamos un testimonio en el que estas ob-ligaciones fungen como una fuente de criterios y compromisos éticos que dinamizan el ethos de la paz.

Con ocasión de la visita del Papa Francisco a Colombia, el 8 de septiembre de 2017 se realizó un encuentro por la reconciliación y la paz nacional. Este encuentro tuvo como epicentro los testimonios de personas vinculadas directamente al conflicto armado, ya fuesen en condición de víctimas o de victimarios. Entre los testimonios presentados, queremos destacar el de Pastora Mira García como el de una personalidad con criterio; esto es, una mujer que, pese a que fue victimizada a los seis años con la muerte violenta de su padre, y revictimizada con 
la muerte violenta de su esposo y sus dos hijos, actualmente lidera movimientos sociales en pro de la paz (Mira, 2018). De ahí que su testimonio inicie exhortando a los colombianos a tener la capacidad de nombrar lo innombrable y perdonar lo imperdonable:

Cuando tenía seis años, la guerrilla y los paramilitares aún no habían llegado a mi pueblo, San Carlos, Antioquia. Aun así, mi padre fue asesinado. Años más tarde pude cuidar al asesino quien ese momento se encontraba enfermo, anciano y abandonado (Mira, 2018).

Consideramos que esta mujer encarna el ethos de la paz en tanto es testigo del principio genésico de la vida buena: cuidar la vulnerabilidad y promover la dignidad de las personas. Si bien la problemática dolorosa de la victimización por el asesinato de su padre pudo ser resuelta bajo dinámicas emocionales de odio, venganza o retaliación; no obstante, Pastora Mira opta por poner en obra una lógica distinta: cuidar la vida vulnerable del victimario. Esta lógica de compasión, perdón y promoción de la vida también puede verse encarnada en acontecimientos posteriores:

En el año 2005 el bloque Héroes de Granada de los paramilitares asesinó a Jorge Aníbal, mi hijo menor. Tres días después de haberlo sepultado atendí herido a un jovencito y lo puse a descansar en la misma casa que había pertenecido a Jorge Aníbal. Al salir de la casa este joven vio las fotos y reaccionó contándonos que él hacía aparte de ese grupo y era uno de sus asesinos. Además, nos narraba cómo lo habían torturado antes de darle muerte. Doy gracias a Dios que con la ayuda de mamita María me dio la fuerza de servirle sin causarle ningún daño a pesar de mi indecible dolor. Ahora coloco este dolor y sufrimiento de las miles de víctimas de Colombia a los pies de Jesús, del Jesús crucificado para que lo una al suyo y a través de la plegaria de su santidad sea transformado en bendiciones y en capacidad de perdón para romper el ciclo de violencia que en las últimas cinco décadas ha sufrido Colombia (Mira, 2018).

La sabiduría cordial que testimonia Pastora Mira no sólo propende por el cuidado de la vida, sino también por la promoción de su dignidad. Así, su "indecible dolor" emocional puede ser comprendido no como una patología masoquista, sino más bien como la ob-ligación y el compromiso ético con un mundo de la vida mejor; un mundo digno en el que el dolor que acarrea la vulnerabilidad espoleada sea transformado erráticamente en capacidades emocionales de amor (Villamil, 2003); es decir, un mundo digno en el que rompamos con el círculo vicioso de la violencia que inmoviliza y paraliza la vida, y demos un salto cualitativo hacia un dinamismo virtuoso capaz de corazonadas comprometidas con la compasión, la confianza, el perdón, la paz y, en suma, la salvación de la vida buena:

Dios bendiga todos los proyectos humanitarios, educativos y productivos, porque son indispensables para crear condiciones que generen esta tan anhelada paz. Que Dios transforme los corazones de quienes se niegan a creer que con Cristo todo puede cambiar y aún no tienen la esperanza de que Colombia puede ser un país en paz y más solidario (Mira, 2018).

A manera de conclusión, podemos considerar lo siguiente: (1) La paz no acontece originariamente como un estado de cosas o un estado de la mente regido por criterios objetivos impersonales, ya sean causales o racionales. (2) La paz acontece como una experiencia emocional cuya valoración encanada guarda sintonía con el principio genésico de la vida, esto es, con el cuidado de la vulnerabilidad céntrica y la promoción de la dignidad excéntrica de la vida de las personas. (3) El lugar del ethos de la paz es el testimonio de personalidades que cultivan una sabiduría emocional errática comprometida con la salud de la vida buena ${ }^{3}$.

\section{Referencias bibliográficas}

Alape, P. (12 de diciembre de 2015). Coordinación Regional del Pacífico Colombiano. Discurso del comandante Pastor Alape de las FARC-EP, en la aceptación de responsabilidades y perdón por la masacre de Bojayá del 2 de mayo de 2002. [Archivo de video]. Recuperado de https://www. youtube.com/watch?v=ZkzQS-KV34s.

Aranguren, J. (1994). Obras completas. Madrid: Trotta.

Arnold, M. (1960). Emoción y personalidad. Buenos Aires: Losada.

Bertalanffy, L. (1976). Teoría General de Sistemas: fundamentos, desarrollos, aplicaciones. México, D.F.: Fondo de Cultura Económico.

Camps, V. (2011). El gobierno de las emociones. Barcelona: Herder.

Castillejo, A., Rueda, E., Agudelo, E., y Quiceno, N. (2015). Procesos de paz y perspectivas democráticas en Colombia. Buenos Aires: CLACSO.

Cortés, I. (2014). “15 años de Filosofía para la Paz. El lugar de la ética en la investigación para la paz”. En: Revista de Paz y Conflictos, 7, 195-209. Recuperado de http://revistaseug.ugr.es/index.php/ revpaz/article/view/1854/2635

$3 \quad$ El modo como acontece el principio genésico de la vida en las experiencias interpersonales de paz es el problema que aborda actualmente nuestro grupo de investigación. Los resultados de esta tarea constituyen la base de un próximo artículo. 
Cortina, A. (2009). Ética de la razón cordial. Educar en la ciudadanía en el siglo XXI. Oviedo: Ediciones Nobel.

Ferro, A. (2016), "Emociones y postconflicto”. En: Revista Semana, 1776, 25-31.

Freire, P. (1981). La ideología y la educación. Reflexiones sobre la no neutralidad de la educación. Rio de Janeiro: Continuum.

Galtung, J. (1964), "An editorial: what is peace research?”. Journal of Peace Research ,1, 1-4. Recuperado de https://www.sagepub.com/sites/ default/files/upm-binaries/47286_Wallensteen, Online_Readings.pdf

Galtung, J. (1975). Essays in Peace Research I. Peace: Research, Education, action. Copenhaguen: Christian Ejlers.

Galtung, J. (1984). ¿Hay alternativas? Cuatro caminos hacia la paz y la seguridad. Madrid: Tecnos.

Galtung, J. (2003). Paz por medios pacíficos. Paz y conflicto, desarrollo y civilización. Bilbao: Bakeaz.

Goleman, D. (1996). La inteligencia emocional. Por qué es más importante que el cociente intelectual. Buenos Aires: Javier Vergara Editor.

Grasa, R. (2010). Cincuenta años de evolución de la Investigación para la Paz. Barcelona: Generalitat de Catalunya/Oficina de Promoción de la Paz y los Derechos Humanos.

Grupo de Memoria Histórica. (2010). Bojayá. La guerra sin límites. Bogotá: Taurus.

Habermas, J. (1987). Teoría de la acción comunicativa. Madrid: Taurus.

Habermas, J. (1998). Facticidad y validez. Sobre el Derecho y el Estado Democrático de Derecho en términos de Teoría Del Discurso. Madrid: Trotta.

Hincapié, L. (2 de mayo de 2014). Víctimas de Bojayá se sanan con el perdón, 12 años después de la masacre. El País. Recuperado de http://www. elpais.com.co/judicial/victimas-de-bojaya-se-sanan-con-el-perdon-12-anos-despues-de-la-masacre.html

Jaramillo, C.; Cabarcas, J.; Villamil, M.; Vallejo, R.; Soto, W. (2018), "El avatar: un modo de ser cibernético cualitativamente estacionario". Folios, 48, 193-206. DOI: http://dx.doi.org/10.17227/folios.48-8143

Lazarus, R. (2000). Estrés y emoción. Manejo e implicaciones en nuestra salud. Bilbao: Desclée de Brouwer.

Martínez, V. (2001). Filosofía para hacer las paces. Barcelona: Icaria.
Martínez, V. (2005). "La Filosofía para la Paz como racionalidad práctica”. En: Investigaciones Fenomenológicas: Anuario de la Sociedad Española de Fenomenología, 4, 87-98.

Martínez, V., Comins, I., y París, S. (2009). "La nueva agenda de la filosofía para el siglo XXI: los estudios para la paz”. En: Convergencia, Revista de Ciencias Sociales, Número Especial, 91-114. Recuperado de http://repositori.uji.es/xmlui/bitstream/handle/10234/92123/36559.pdf?sequen$\mathrm{ce}=1$

Mira, P. (2018). “Testimonio”. En: El País: El testimonio de Pastora Mira Gracía. La víctima que conmovió a Francisco. En línea, recuperada de (https:// www.elpais.com.co/colombia/el-testimonio-de-pastora-mira-garcia-la-victima-que-conmovio-a-francisco.html). Visitada: 26/04/2019.

Mockus, A., Murraín, H., y Villa, M. (coords). (2012). Antípodas de la violencia. Desafíos de cultura ciudadana para la crisis de (in)seguridad en América Latina. Bogotá: Corpovisionarios - Banco Interamericano de Desarrollo.

Mouffe, C. (2002). Politics and passions. Londres: CSD.

Neumann, J; Morgenstern, O. (1944). Theory of Games and Economic Behavior. Princeton: Princeton University Press.

Nicolson, H. (1950). Diplomacy. Oxford: Oxford University Press.

Norman, J. (1950). Contemporany International Relations Readings. Cambridge: Harvard University Press.

Nussbaum, M. (2001). Paisajes del pensamiento. La inteligencia de las emociones. Barcelona: Páidos,

Nussbaum, M. (2006). El ocultamiento de lo humano. Repugnancia, vergüenza y ley. Buenos Aires: Katz Editores.

Nussbaum, M. (2012). Emociones políticas. ¿Por qué el amor es importante para la justicia? Barcelona: Paidós.

Organización de las Naciones Unidas (1945). Declaración Universal de los Derechos Humanos. Recuperado de http://www.un.org/spanish/aboutun/hrights.htm

Organización de las Naciones Unidas (2000). Manifiesto 2000 para una cultura de paz y no violencia. Recuperado de http://www3.unesco.org/ manifesto2000/sp/sp_manifeste.htm

Organización de las Naciones Unidas (2012). Textos Fundamentales. París: ONU. 
Pascal. (1980). Pensamientos. Buenos Aires: Aguilar.

Prinz, J. (2004). Gut Reactions. A perceptual Theory of Emotion. New York: Oxford University Press.

Prinz, J. (2007). The Emotional Construction of Morals. Oxford: Oxford University Press.

Rapoport A. (1999). Peace, Definitions and Concepts of. In L. Kurtz (Ed.), Encyclopedia of Violence, Peace and Conflict. San Diego: Academic Press.

Rostow, W. (1960). The Stages of Economic Growth. Cambridge: Cambridge University Press.

Sáez, L. (2009). Ser errático. Una ontología crítica de la sociedad. Madrid: Trotta.

Sáez, L. (2015). El ocaso de Occidente. Barcelona: Herder.

Scheler, M. (1913). Ordo amoris. Gramática de los sentimientos. Barcelona: Crítica (2003).

Scheler, M. (1927). La idea de la paz perpetua y el pacifismo. Barcelona: Alba Editorial.

Scheler, M. (1913). Ética. Nuevo ensayo de fundamentación de un personalismo ético. Madrid: Caparrós Editores.

Scheler, M. (1957). El santo, el genio y el héroe. Buenos Aires: Nova

Solomon, R. (2007). Ética emocional. Una teoría de los sentimientos. Barcelona: Paidós.

Urdal, H. (2014). “50 years of peace research: An introduction to the Journal of Peace Research anniversary special issue". En: Journal of Peace Research, 51(2), 139-144. doi: 10.1177/0022343314521649

Vega, M.; González, G. (2016). "Bullying en la escuela secundaria. Factores que disuaden o refuerzan el comportamiento agresor de los adolescentes”. En: Revista Mexicana de Investigación Educativa, 21(71), 1165-1189. Recuperado de http:// www.redalyc.org/pdf/140/14047430008.pdf

Villamil, M. (2003). Fenomenología del cuerpo y su mirar. Bogotá: Universidad Santo Tomás.

Villamil, M. (2009). Valores y derechos humanos. Implicaciones jurídicas y pedagógicas. Bogotá: Bonaventuriana.

Villamil, M. (2017). Emociones humanas y ética. Para una fenomenología de las experiencias personales erráticas. Bogotá: Pontificia Universidad Javeriana.
Waldenfels, B. (2006). "El sitio corporal de los sentimientos”. En: Signos Filosóficos, 8 (15), 129-150. Recuperado de http://www.redalyc.org/articulo. oa?id=34301505

Zubiri, X. (1986). Sobre el hombre. Madrid: Alianza.

Miguel Ángel Villamil Pineda (http://orcid. org/0000-0002-3397-3429) es Doctor en Filosofía de la Pontificia Universidad Javeriana; Magíster en Filosofía Latinoamericana y Licenciado en Filosofía y Letras de la Universidad Santo Tomás. E-mail: miguel. villamil@usantotomas.edu.co

José Miguel Cabarcas (https://orcid.org/0000-00031753-0457) es Doctor de la Facultad de Ciencias Exactas de la Universidad Nacional de La Plata, Argentina. Físico de la Universidad Nacional de Colombia. E-mail: josecabarcasl@usantotomas.edu. co

Rubén Darío Vallejo (https://orcid.org/0000-00022659-3313) es Doctor en Educación de la Universidad de la Salle de Costa Rica; Magíster en Educación de la Universidad Santo Tomás y Licenciado en Ciencias de la Educación en Lingüística y Literatura de la Universidad Distrital Francisco José de Caldas. Email: rubenvallejo@usantotomas.edu.co

Wilson Hernando Soto (https://orcid.org/0000-00020139-0544) es Doctor y Magíster en Educación de la Universidad Pedagógica Nacional e Ingeniero Mecánico de la Universidad Nacional de Colombia. E-mail:wilsonsoto@usantotomas.edu.co

Fray Alberto René Ramírez (https://orcid.org/00000001-8560-2518) es Doctor en Filosofía de la Universidad Nacional de Educación a Distancia de España; Magíster en Filosofía Latinoamericana y Licenciado enFilosofía y Letras delaUniversidad Santo Tomás de Colombia. E-mail: frayalbertoramirez@ usantotomas.edu.co

Recebido em 17.10.2018

Primeira Decisão Editorial em 23.04.2019 Aceito em 19.05.2020 